\title{
RELAÇÕES ENTRE O DESENVOLVIMENTO INFANTIL E AS PRÁTICAS PEDAGÓGICAS REPRESENTADAS PELOS PROFESSORES DE EDUCAÇÃO FÍSICA
}

\author{
Bruno Viviani dos Santos \\ Pedro Humberto Faria Campos
}

Resumo

O presente estudo objetivou analisar as relações entre o desenvolvimento infantil e as práticas pedagógicas representadas pelos professores de Educação Física do Ensino Fundamental II, nos municípios de Belford Roxo, Nova Iguaçu, Nilópolis, Mesquita e Queimados, no estado do Rio de Janeiro. Para a coleta de dados, foi aplicado um questionário com questões abertas a 103 professores, que deveriam explicar como o jogo de futsal, o jogo de queimada e a dança contribuem para o desenvolvimento dos alunos nos aspectos afetivo, cognitivo e social. Os dados foram submetidos a uma análise do programa Alceste (Analyse Lexicale par Contexte d'un Ensemble de Segment de Texte). Os resultados apontam para uma representação social das práticas pedagógicas estudadas dissociadas dos conhecimentos das novas abordagens pedagógicas do campo da Educação Física escolar relacionadas ao desenvolvimento infantil.

Palavras-chave: desenvolvimento infantil; educação física escolar; representações sociais.

\section{RELATIONSHIPS BETWEEN CHILD DEVELOPMENT AND PEDAGOGICAL PRACTICES REPRESENTED BY PHYSICAL EDUCATION TEACHERS}

\begin{abstract}
The present objective study was to analyze the relations between child development and pedagogical practices represented by Physical Education teachers from Elementary School II, from the municipalities of Belford Roxo, Nova Iguaçu, Nilópolis, Mesquita and Queimados, and not from the State of Rio de Janeiro. For a row of data, a questionnaire with open questions was applied to 103 teachers, who must explain how futsal or dodgeball game and dance contribution to the development of some of the affective, cognitive and social aspects. You receive a submerged foramen for an analysis of the Alceste program. The results aim at a social representation of the pedagogical practices carried out in the dissociation between two different educational approaches in the field of School Physical Education related to the child's development.
\end{abstract}

Keywords: child development; school physical education; social representations.

\section{RELACIONES ENTRE EL DESARROLLO INFANTIL Y LAS PRÁCTICAS PEDAGÓGICAS REPRESENTADAS POR LOS DOCENTES DE EDUCACIÓN FÍSICA}

Resumen

El presente estudio objetivo fue analizar la relación entre el desarrollo infantil y las prácticas pedagógicas representadas por maestros de Educación Física de la Escuela Primaria II, de los municipios de Belford Roxo, Nova Iguaçu, Nilópolis, Mesquita y Queimados, y no del Estado de Río de Janeiro. Para una cola de datos, se aplicó un cuestionario con preguntas abiertas a 103 maestros, quienes deben explicar cómo el juego de fútbol sala o el juego de dodgeball y la danza contribuyen al desarrollo de algunos de los aspectos afectivos, cognitivos y sociales. Recibe un agujero sumergido para un análisis del programa ALCESTE. Los 
resultados apuntan a una representación social de las prácticas pedagógicas llevadas a cabo en la disociación entre dos enfoques educativos diferentes en el campo de la educación física escolar relacionada con el desarrollo del niño.

Palabras clave: desarrollo infantil; educación física escolar; representaciones sociales.

\section{INTRODUÇÃO}

Inicialmente, no Brasil, a formação do professor de Educação Física era voltada para a prática pedagógica relacionada ao desenvolvimento do rendimento físico e da eugenia, por meio de exercícios ginásticos (BRACHT, 2014), perspectiva que não visava ao desenvolvimento integral do aluno. Essas concepções eram chamadas higienista e militarista, pois consideravam a Educação Física como disciplina essencialmente prática, não havendo distinção evidente entre a Educação Física e a instrução militar.

Com a implementação da ditadura militar, em 1964, passa a vigorar nas práticas pedagógicas do professor de Educação Física um modelo denominado esportivista, que era associado ao esporte, especialmente ao futebol. Nesse contexto, cabe destacar que muitos professores eram ex-atletas, militares, médicos, o que tornava evidente uma prática bastante centralizadora, baseada na repetição exacerbada dos movimentos esportivos, na valorização do desenvolvimento do físico e da moral e, também, na falta de preocupação com o desenvolvimento geral do aluno (DARIDO, 2011). Neste cenário, a própria atividade física em si mesma era percebida como promotora do desenvolvimento (motor) e a discussão sobre a didática da EFe era precária ou inexistente.

A partir da década de 1980, em oposição às vertentes mais tecnicistas, esportivistas e biológicas, surgem novos movimentos no campo da Educação Física escolar (EFe), tendo em comum a tentativa de romper com os modelos até então vigentes (BETTI, 2013; DARIDO, 2011). Esses movimentos contribuíram para a construção das novas abordagens pedagógicas no campo da EFe, proporcionando a ampliação dos conhecimentos relacionados ao desenvolvimento infantil na prática pedagógica do professor de Educação Física (LE BOUCH, 1983). Além disso, com a publicação dos Parâmetros Curriculares Nacionais (PCN) de Educação Física (BRASIL, 1998) e com a promulgação da Lei de Diretrizes e Bases da Educação Nacional no 9.394/1996, a disciplina de Educação Física passa a ser considerada componente curricular obrigatório, que aos olhos da lei possui objeto de estudo e conhecimentos próprios ligados aos elementos da cultura corporal de movimento (ginástica, capoeira, danças, lutas, jogos, conhecimento sobre o corpo e esportes). Ou seja, ela passa a ser considerada componente curricular como as demais disciplinas do currículo escolar (BRASIL, 1996).

Diante dos novos conhecimentos ligados à cultura corporal de movimento, a prática pedagógica da EFe passa a contribuir para o desenvolvimento integral do aluno, isto é, objetiva desenvolver os aspectos afetivo, cognitivo, motor e social (PIAGET, 2003; 2007; COLL et al., 2004).

Pesquisas no campo da EFe (COTRIM et al., 2011; FORTES et al., 2012; WATANABE, BIM, 2012; BERTINI JUNIOR, TASSONI, 2013; TENÓRIO et al., 2015) apontam carência do aprendizado das abordagens teóricas do campo da EFe, inconsistência teórica por parte dos professores em relação a qual abordagem pedagógica embasa o seu trabalho e a existência de intencionalidades pedagógicas pouco sistematizadas no processo de ensino-aprendizagem nas aulas de Educação Física. Diante desse cenário, a prática pedagógica do professor de Educação Física parece se afastar dos preceitos teóricos que subsidiam e legitimam sua disciplina no currículo escolar. 
Neste cenário, um conjunto de pesquisadores interessados especialmente na EFe, pertencentes a diferentes instituições e grupos de pesquisa, buscou fundamentar o estudo das concepções e práticas escolares e formativas da EF, na chamada Teoria das Representações Sociais (MOSCOVICI, 1976, 2012; JESUINO, 2018). Os estudos sobre representações sociais visam a compreensão das construções de significados, conhecimentos, crenças, opiniões, atitudes e valores que são adquiridas e compartilhadas pelos grupos, por meio das interações cotidianas com relação a um objeto social. Assim, a teoria das representações sociais visa demonstrar, como o grupo constrói um sistema cognitivo capaz de dar sentido à situação percebida, permite a compreensão das relações entre as ações dos grupos e suas crenças, bem como aos comportamentos empreendidos. Ela ainda possibilita a criação de estratégias cognitivas, orienta as ações e as relações sociais (ABRIC, 2001; ROUQUETTE, 2003). Esta perspectiva converge com as preocupações com a didática e práticas educativas da EF nas escolas.

Neste sentido, os professores de Educação Física, ao logo da formação na universidade, produziram crenças, opiniões, atitudes e valores que foram adquiridas e compartilhadas, por meio das interações cotidianas entre os diversos grupos que os mesmos compõem. Ou seja, certos conteúdos, práticas foram filtradas, construídas e a reconstruídas internamente produzindo significados que permitem o entendimento e a interpretação do ambiente social.

Com isso, os estudos sobre as Representações Sociais e a EFe (BARBOSA, 2001; SÁ, 2006; PEREIRA, 2008; CUNHA, 2009) revelam que a representação social da prática pedagógica da Educação Física está ligada à formação esportiva, ao aspecto da recreação, à noção genérica de "saúde", ou seja, à ideia da prática física sem refletir sobre a importância do exercício físico para o desenvolvimento do ser humano e a falta de consistência teórica no uso das novas abordagens pedagógicas do campo da EFe.

No estudo realizado por Retondar (2009) foi observado que os professores justificavam sua prática pedagógica apontando a abordagem psicomotora como suporte teórico, considerando o nível de complexidade do ensino e as diferentes faixas etárias. Então, ao relacionarmos a presente proposta de pesquisa com o referido estudo, avançamos na direção de como os professores de Educação Física relacionam a suas práticas pedagógicas, ou seja, as atividades que ele ministra em suas aulas com o desenvolvimento infantil, isto é, o desenvolvimento das dimensões afetivas, cognitivas, sociais, visto que as novas abordagens no campo da EFe, por exemplo, a psicomotora, possibilitam embasamento teórico acerca do desenvolvimento integral do aluno.

Vasconcelos e Campos (2016), em sua pesquisa, identificaram a ancoragem das representações sociais da EFe, elaboradas por professores de Educação Física, nas abordagens teóricas presentes no campo mais amplo da EF. Como resultados, os autores apontam que os sujeitos pesquisados de Educação Física valorizam de forma expressiva o aspecto prático da disciplina enaltecendo, predominantemente, os elementos que recorrem ao esporte e aos jogos, representando o elemento lúdico como o principal recurso da prática pedagógica da disciplina. Os sujeitos da pesquisa entendem como objetivo principal a ser alcançado por meio do esporte, dos jogos e do movimento o desenvolvimento do aluno. Segundo os autores, os sujeitos apresentam uma representação social do desenvolvimento infantil do tipo naturalista, como se o desenvolvimento das crianças (dos alunos) fosse espontaneamente estimulado por atividades físicas "genéricas"; deste modo, não seria necessária uma didática especializada ou aprofundada para as aulas de EF nas escolas. Os autores concluem que os professores organizam suas práticas em princípios metodológicos que não estão estruturados em apenas uma das abordagens. Isso sugere que a prática da EFe pode estar ancorada em um mix de noções, oriundas de algumas abordagens, provavelmente coordenada pela chamada "experiência prática", ou seja, em "saberes da prática" (TARDIFF, 2014). 
De um ponto de vista histórico, práticas pedagógicas nas aulas de Educação Física, em seu passado, priorizavam o componente exclusivamente motor, devido às abordagens ligadas às áreas médica e militar. A partir da década de 1980, novas abordagens e diretrizes, sobretudo sustentadas pela Lei de Diretrizes e Bases da Educação Nacional de 1996 (BRASIL, 1996) e pelas Bases Nacionais Comum Curriculares (BRASIL, 2017), são promovidas, como políticas públicas com o intuito de romper a cultura antiga hegemônica no cenário escolar da Educação Física; apesar destas mudanças, estudos apontam ainda, por parte de alguns professores, certo desconhecimento acerca das abordagens oriundas das Ciências Sociais e da Psicologia, que ampliaram a visão do campo da EFe, proporcionando conhecimentos sobre como a criança se desenvolve. Entre elas, a abordagem psicomotora de Le Boulch (1983) proporciona uma visão integral da criança que, por meio do movimento corporal, busca desenvolver as dimensões afetiva, cognitiva, motora e social.

Com isso, de que forma a relação entre o desenvolvimento infantil e as práticas pedagógicas são representadas pelos professores de Educação Física?

Assim, o presente estudo tem como objetivo analisar as relações entre o desenvolvimento infantil e as práticas pedagógicas representadas pelos professores de Educação Física do Ensino Fundamental II.

\section{PROCEDIMENTOS METODOLÓGICOS}

Este estudo é caracterizado como uma pesquisa qualitativa, utilizando a amostragem por conveniência, do tipo exploratória, pois buscou aproximar a Teoria das Representações Sociais (TRS) com o campo da Educação Física escolar (EFe), mais precisamente, as práticas escolares dos professores do componente curricular especificado.

A seleção dos participantes ocorreu, primeiro, pela identificação das escolas públicas e privadas da Baixada Fluminense, nos municípios de Belford Roxo, Nova Iguaçu, Nilópolis, Mesquita e Queimados na Secretária de Estado de Educação do Rio de Janeiro. Posteriormente, os pesquisadores selecionaram as escolas e os participantes da pesquisa utilizando a amostra do tipo não probabilística por conveniência, definida mediante os critérios: trabalhar no mínimo de três anos de experiência no magistério; atuantes em escolas públicas e privadas; em turmas de segundo segmentos do Ensino Fundamental II.

O grupo pesquisado foi composto por 103 professores de Educação Física, da Baixada Fluminense. Desses, 75 atuam em escolas públicas, 24, em escolas privadas, três trabalham tanto em escola pública quanto em escola privada, e apenas um não informou a instituição na qual trabalha.

Como instrumento de coleta de dados, foi utilizado um questionário aberto, apresentado ao professor de Educação Física, no qual havia três imagens com atividades que são praticadas nas aulas de Educação Física (DARIDO, SOUZA JUNIOR, 2011), sendo elas: o jogo de futsal, o jogo de queimada e a dança. Para cada imagem foram apresentadas três perguntas aos professores, sobre como a atividade representada contribui para o desenvolvimento dos alunos em cada um dos aspectos específicos do desenvolvimento, ou seja, aspectos afetivo, cognitivo e social. Assim, para cada atividade encontramos três justificativas sobre o seu impacto em uma dimensão específica do desenvolvimento; o conjunto destas respostas são tratadas como discursos, conjunto de enunciados que carregam os significados atribuídos pelos sujeitos. As tiras de desenhos são apresentadas na Figura 1: jogo de futsal, na Figura 2: jogo de queimada e, na Figura 3, dança. 

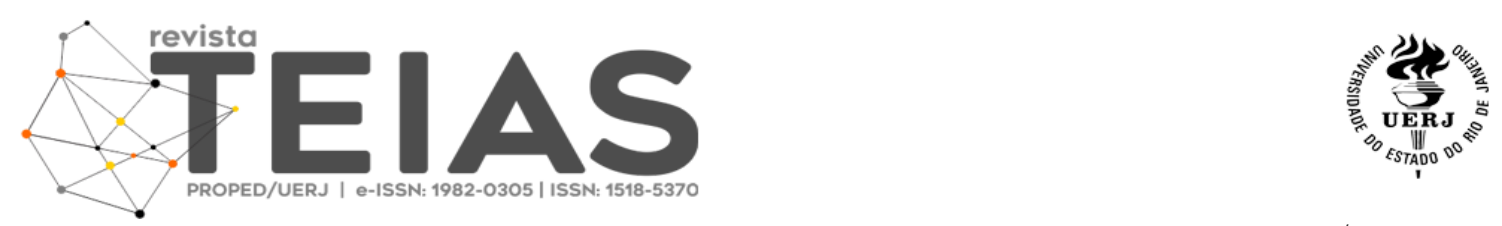

DOI: $10.12957 /$ teias. 2020.45956

Figura 1: Jogo de futsal

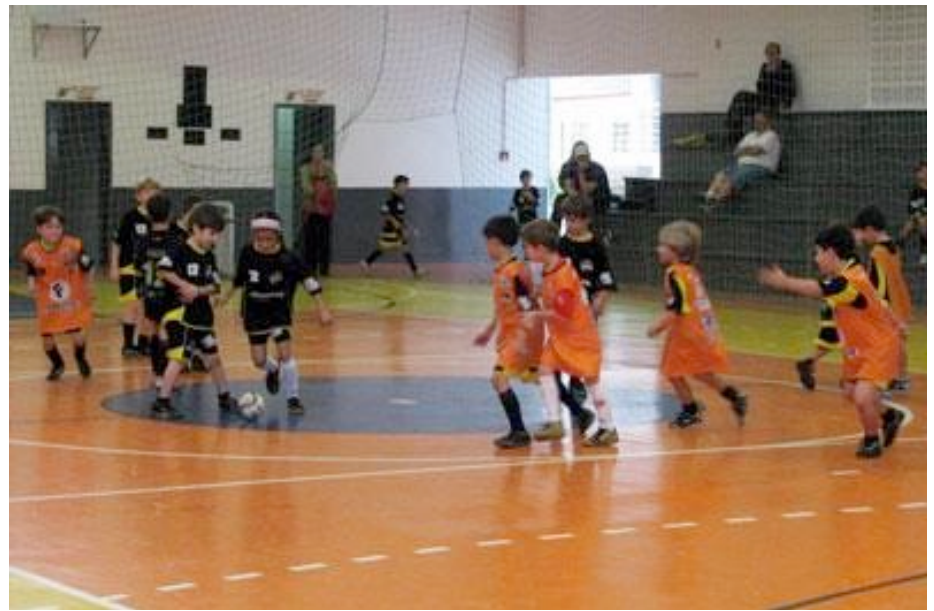

Fonte: https://br.depositphotos.com/stock-photos/futsal.html, 2016.

Figura 2: Jogo de queimada

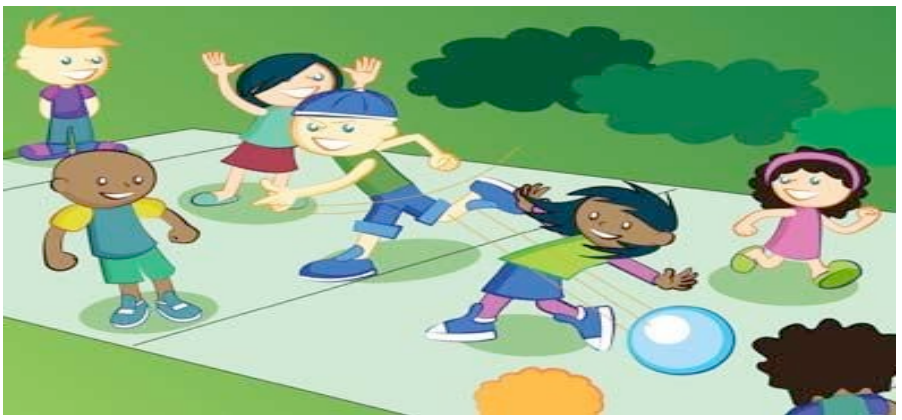

Fonte: http://educacaofisicaparaeducadores.blogspot.com/2013/04/variacoes-de-queimada.html, 2016.

Figura 3: Dança

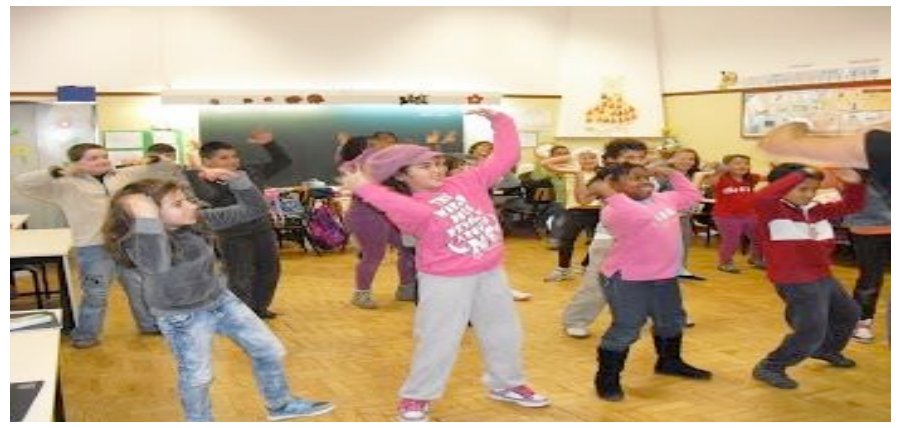

Fonte: http://portalcrescer.blogspot.com/2011/09/importancia-da-danca-na-educacao.html, 2016.

Um estudo-piloto realizado previamente, com 24 professores de Educação Física, com imagens de cinco atividades (corrida, o jogo de futsal, pique pega, o jogo de queimada e a dança) que são normalmente praticadas nas aulas de Educação Física (DARIDO, SOUZA JUNIOR, 2011) tendo o objetivo de analisar a identificação das imagens como remetendo de fato às atividades referenciadas no estudo; o impacto evocativo (MOLINER, 2016) de cada imagem e o 
tipo de resposta estimulada em relação ao desenvolvimento. Após a análise de conteúdo das respostas dos professores, foram selecionadas as atividades: jogo de futsal, jogo de queimada e dança.

Para o procedimento de análise dos dados coletados de cada atividade (o jogo de futsal, o jogo de queimada e a dança) e das três formas básicas do desenvolvimento (cognitivo, afetivo e social), utilizamos o software de análise lexicográfica de dados textuais denominado Alceste (Analyse Lexicale par Contexte d'un Ensemble de Segment de Texte) (REINERT, 1986). Este programa realiza a análise estatística a partir de um único arquivo de texto, que pode ser uma entrevista, um questionário, ou outro tipo de material textual, denominado Unidade de Contexto Inicial (UCI).

O Alceste reconhece as unidades de contexto iniciais UCI dividindo-as e classificando-as em Unidades de Contextos Elementares (UCE), que são pequenos segmentos do texto, na maior parte das vezes, do tamanho de três linhas dimensionadas pelo programa, em que se respeita a ordem de aparição que elas têm no corpus semântico.

Utilizamos no presente estudo, o primeiro nível de análise, que consiste na Classificação Hierárquica Descendente $(\mathrm{CDH})$, que consiste em separar as UCEs em várias classes do vocabulário que as compõem, de tal forma que seja obtido o maior valor possível numa prova de x2. Em seguida, o programa apresenta também as oposições entre as classes sob a forma de uma árvore (dendograma). Um segundo nível de análise, inclui a relação entre variáveis previamente definidas associadas a cada classe. No presente estudo, as classes encontradas puderam ser classificadas como sendo discursos associados a cada uma das imagens (danças, futsal ou queimada) e a cada um dos aspectos específicos do desenvolvimento (afetivo, cognitivo ou social).

\section{RESULTADO E DISCUSSÃO}

A análise lexicográfica realizada com auxílio do Alceste encontrou sete classes, divididas em dois blocos, considerando a proximidade / distância entre os léxicos: a Classe 1 comporta 17\% do corpus; a Classe 2 corresponde a 23\%; a Classe 3 conta com $11 \%$; a Classe 4 obteve 20\%; a Classe 5 representa $7 \%$; a Classe 6 participa com $12 \%$; e a Classe 7 com $10 \%$.

De fato, foram encontrados dois blocos, sendo que as Classes 1 e 2, juntas, dão consistência aos grupos de palavras associadas ao primeiro bloco respondendo, ambas, por 40,0\% do total e, em segundo plano, associadas às Classes 6 e 7, compõem 62\%. No segundo bloco é a Classe 4 que oferece maior sentido, com $20 \%$ dos léxicos associados. Em seguida, o programa Alceste apresentou também as oposições entre as classes sob forma de dendograma.

A Tabela 1 mostra o bloco 1 - Cooperação, Convivência e Motivação e o bloco 2 Estratégia, Raciocínio e Movimentos, ou seja, os dados tratados pelo software Alceste.

Para a nomeação dos blocos, foi realizada a análise de conteúdo, do tipo temática, após a análise lexical do material textual do software Alceste. 
Tabela 1: Dendograma das contribuições do jogo de futsal, do jogo de queimada e da dança para os aspectos afetivo, cognitivo e social do aluno.

\begin{tabular}{|c|c|c|c|c|c|c|}
\hline & \multicolumn{2}{|c|}{$\begin{array}{c}\text { Bloco } 1 \text { - Cooperação, } \\
\text { Convivência e } \\
\text { Motivacão }\end{array}$} & & \multicolumn{3}{|c|}{$\begin{array}{l}\text { Bloco 2 - Estratégia, } \\
\text { Raciocínio e } \\
\text { Movimentos Corborais }\end{array}$} \\
\hline $\begin{array}{c}\text { Classe } 1 \\
17 \%\end{array}$ & $\begin{array}{c}\text { Classe } 2 \\
23 \%\end{array}$ & $\begin{array}{c}\text { Classe } 6 \\
12 \%\end{array}$ & $\begin{array}{c}\text { Classe } 7 \\
10 \%\end{array}$ & $\begin{array}{c}\text { Classe } 4 \\
20 \%\end{array}$ & $\begin{array}{c}\text { Classe } 5 \\
7 \%\end{array}$ & $\begin{array}{c}\text { Classe } 3 \\
11 \%\end{array}$ \\
\hline Presença & Presença & Presença & Presença & Presença & Presença & Presença \\
\hline $\begin{array}{c}\text { saber } \\
\text { perder } \\
\text { amizade } \\
\text { papel } \\
\text { convívio } \\
\text { time } \\
\text { importância } \\
\text { aumento } \\
\text { colega } \\
\text { coletividade } \\
\text { grupo } \\
\text { lidar } \\
\text { ganhar } \\
\text { integração } \\
\text { lidar }\end{array}$ & $\begin{array}{c}\text { esporte } \\
\text { derrota } \\
\text { solidariedade } \\
\text { companheiro } \\
\text { vitória } \\
\text { competição } \\
\text { respeito } \\
\text { laço } \\
\text { motivação } \\
\text { amigo } \\
\text { cooperação } \\
\text { próximo } \\
\text { emocional } \\
\text { espírito } \\
\text { socialização }\end{array}$ & $\begin{array}{c}\text { cultura } \\
\text { favorece } \\
\text { dança } \\
\text { interpessoal } \\
\text { diferença } \\
\text { social } \\
\text { oportunidade } \\
\text { interação } \\
\text { forma } \\
\text { integração } \\
\text { processo } \\
\text { reconhecer } \\
\text { preconceito } \\
\text { conhecimento } \\
\text { estilo }\end{array}$ & $\begin{array}{l}\text { positivo } \\
\text { sensação } \\
\text { negativo } \\
\text { timidez } \\
\text { autoestima } \\
\text { felicidade } \\
\text { confiança } \\
\text { domínio } \\
\text { componente } \\
\text { emoção } \\
\text { expressão } \\
\text { depende } \\
\text { valor } \\
\text { corporal } \\
\text { prazer }\end{array}$ & $\begin{array}{l}\text { tática } \\
\text { estratégia } \\
\text { rápido } \\
\text { regra } \\
\text { raciocínio } \\
\text { jogo } \\
\text { pensamento } \\
\text { elaboração } \\
\text { requer } \\
\text { situação } \\
\text { técnica } \\
\text { aplicação } \\
\text { decisão } \\
\text { jogada } \\
\text { jogos }\end{array}$ & $\begin{array}{c}\text { planejamento } \\
\text { tempo } \\
\text { reação } \\
\text { controle } \\
\text { solucionar } \\
\text { personalidade } \\
\text { problemas } \\
\text { estratégia } \\
\text { dentre } \\
\text { raciocínio } \\
\text { vencer } \\
\text { defender } \\
\text { desenvolvi } \\
\text { capacidade } \\
\text { atingir }\end{array}$ & $\begin{array}{c}\text { ritmo } \\
\text { coreografia } \\
\text { sequência } \\
\text { movimentos } \\
\text { corpo } \\
\text { memorização } \\
\text { história } \\
\text { manifestação } \\
\text { dança } \\
\text { concentração } \\
\text { conhecimento } \\
\text { exploração } \\
\text { passos } \\
\text { corporais } \\
\text { música }\end{array}$ \\
\hline
\end{tabular}

Fonte: Elaborada pelos autores, 2019.

\section{Bloco 1 - Cooperação, Convivência e Motivação \\ Classe 1 - Título: Atividade de Grupos e Competição}

Esta classe apresenta um discurso que aparece tipicamente em resposta à imagem do jogo de queimada e à questão sobre o desenvolvimento social; este discurso está organizado em torno da ideia de que essa atividade promove a convivência, a noção de coletividade, fortalece a amizade e o grupo, promovendo a "aprendizagem" do "saber ganhar" e "saber perder". Estes discursos apresentam ausência completa de relação com a imagem da dança e as perguntas sobre o desenvolvimento cognitivo. Supomos que, segundo o discurso desta classe, o jogo de queimada promove um desenvolvimento social em um sentido genérico. Frases Típicas da Classe 1:

\footnotetext{
"Relacionamento com o próprio time e adversários desenvolve respeito, amizade colaboração".

"Contribui viabilizando o saber ganhar, saber competir, o saber lidar com resultados."

"Facilita a integração e o aumento da autoestima."
} 
"Depende da ocasião, pode ser trabalhado a parte afetiva, pois normalmente na queimada, é possível verificar um gostar do outro ou não."

Os discursos dos professores de Educação Física induzidos por "desenvolvimento social" e do "jogo de queimada" mostram indícios de falta de intervenção pedagógica nas práticas relacionadas; parecem indicar que as atividades de competição, em si mesmas, por serem "em grupos", desenvolveriam sentimentos, como respeito e autoestima do aluno. Há um discurso recorrente de "saber ganhar" e "saber perder" sem explicações sobre como "ganhar" ou "perder" podem ser educativos e estimular o desenvolvimento social.

De acordo com Betti e Zuliani (2002), a Educação Física como componente curricular da educação básica deve introduzir e integrar o aluno à cultura corporal de movimento, formando o cidadão que vai produzi-la, reproduzi-la e transformá-la, possibilitando o aprimoramento do desenvolvimento afetivo, cognitivo, motor e social. Com isso, a utilização do jogo pelo professor de Educação Física, como ferramenta pedagógica e com objetivo claro, pode contribuir para o desenvolvimento do aluno, porque não envolve apenas um componente externo ou prático (a ação), mas também um componente simbólico (a representação do corpo e suas possibilidades de ação), isto é, o jogo poderá ter situações que envolvam a criação de estratégias de jogo, a cooperação entre os participantes, de forma que todos participem da brincadeira, o respeito mútuo, levando a sentimentos morais, como honestidade, companheirismo, fair play e justiça.

\section{Classe 2 - Título: Motivação, Vitória e Derrota}

Esta classe é bem próxima da Classe 1, apresenta um discurso típico da indução pela imagem do "futsal" e pela questão sobre o "desenvolvimento afetivo"; seu conteúdo e do futsal que está organizado em torno da ideia de que esta atividade promove o esporte, a solidariedade, a cooperação e a competição, ensina a lidar com a derrota e a vitória, faz desenvolver a motivação e o respeito. Também aqui, a dança e o desenvolvimento cognitivo são variáveis estão completamente ausentes desta classe. Com base na análise apresentada, observamos que, segundo o discurso desta classe, o futsal promove um desenvolvimento afetivo em um sentido de "realização" coletiva, ou seja, visa à cooperação e motivação para ganhar ou perder. Frases Típicas da Classe 2:

\footnotetext{
"Trabalha o emocional da criança durante o confronto para a vitória ou a derrota."

"Cooperação, respeito e solidariedade ao lidar com vitórias e derrotas."

"Por ser um esporte, predominante e preferencial dos alunos, este desenvolvimento naturalmente aparece na quadra."

"O futsal ajuda na socialização, na aceitação, no respeito às individualidades das crianças e, principalmente, no espírito de equipe."
}

A Classe 2, para os indivíduos pesquisados, aponta que o futsal promove a noção genérica de coletividade, de amizade e da cooperação — formas do desenvolvimento social —, e isto aparece sem nenhuma especificação: parece ser natural do jogo. Também é apresentada nesta classe, a desvinculação entre esta modalidade e o desenvolvimento cognitivo. Ainda em relação ao futsal, esta atividade é reforçada como promotora de uma visão da "coletividade" e, nesta classe, associada ao desenvolvimento afetivo que, por sua vez, é visto em termos de "aprender a ganhar ou perder"; como se, com a vitória ou a derrota o aluno aprendesse a ganhar e a perder simplesmente vencendo ou perdendo. As formas de organização social e as cargas afetivas que envolvem as vivências grupais não foram apontadas, nem discutidas pelos professores. 
O discurso apresentado pelos professores pesquisados nos possibilita afirmar que tal visão não se encontra amparada por uma abordagem psicomotora. Segundo Le Boulch (1983), a abordagem psicomotora visa ao desenvolvimento integral do aluno, por meio do movimento, ou seja, com a intervenção do professor de Educação Física, o movimento pode contribuir para que o aluno interaja com o meio ambiente, modificando-o e se modificando e, assim, interiorizando os conhecimentos adquiridos pelas trocas sociais.

\section{Classe 6 - Título: A dança e o "desenvolvimento cultural"}

Esta classe apresenta um discurso típico que aparece vinculado à imagem da "dança" e "associado à dança e ao desenvolvimento afetivo". Ela está associada a valorização da cultura e do favorecimento e fortalecimento das interações. É um discurso genérico, isto é, sem relação especifica ou aprofundada entre os elementos propriamente afetivos: os sujeitos respondem a questão proposta em termos de "desenvolvimento afetivo" falando de diversidade cultural, diferenças, integração social; é um discurso "em resposta a uma questão afetiva", mas que não apresenta uma visão do desenvolvimento específico deste aspecto, nem respostas com conotação emocional direta específica com a dimensão afetiva e de pouca consistência com baixa associatividade interna entre as palavras associadas a esta classe. Frases Típicas da Classe 6:

\footnotetext{
"Mostrar e reconhecer na dança a diversidade cultural como forma de aprendizagem social."

"A dança no contexto escolar nos traz uma rica e variada forma de conhecer, relembrar e pensar as culturas de um determinado grupo social."

"Interação constante com o grupo; descontração, relaxamento."

"Cria oportunidades para que os alunos aprendam a respeitar as diferenças e construir soluções coletivas para favorecer um melhor desempenho."
}

A partir das frases típicas dos sujeitos da pesquisa em relação a dança e o desenvolvimento afetivo, apontamos para uma carência teórica entre o ensino da dança e suas contribuições para a dimensão afetiva; e a ideia de que a dança promove a "cultura" ao passo que os alunos dançam. Podemos interrogar em qual sentido o "respeito às diferenças culturais" é visto como um desenvolvimento "afetivo; do mesmo modo, fica a interrogação sobre a ausência de elementos culturais no futsal e no jogo de queimados; ou seja, o discurso sinaliza uma concepção de cultura como "atividade artística".

A prática pedagógica da dança é muito importante na medida em que possibilita aos alunos uma ampliação da visão sobre a expressão corporal e a comunicação por meio dos gestos na presença de ritmos, sons e da música e que participa da construção do esquema corporal (LE BOULCH, 1983; BRASIL, 1998).

Classe 7 - Título: Autoestima, confianç e grupo

Esta classe se apresenta muito semelhante e relacionada à Classe 6, com um discurso associado à imagem da "dança" e às perguntas relativas tanto ao "desenvolvimento afetivo" quanto ao "desenvolvimento social". Afirma que esta atividade trabalha ou favorece a autoestima, o desenvolvimento de sentimentos positivos, a felicidade, reduz a timidez, fortalece a confiança e introduz a noção genérica de "cooperação". O fortalecimento da confiança e da autoestima aparecem associados à noção de grupo, sem esclarecer o que é definido como "grupo" nesta atividade, pois não fica claro se o que é focado é a dança expressiva espontânea ou apresentações grupais, que necessitariam um trabalho de coordenação das ações corporais dos participantes. Pode 
supor uma visão que a "socialização" espontaneamente promove o desenvolvimento afetivo. Frases Típicas da Classe 7:

"Reforçando os valores de autoestima, segurança e confiança."

"Contribui com a socialização com os outros componentes do grupo."

"Sensação de pertencimento a um grupo."

"Cooperação, prazer, sensação de alegria, melhora na autoestima. Por meio da expressão corporal, algumas características da criança podem ser observadas e desenvolvidas como, por exemplo, a timidez e a desenvoltura."

É possível observar nas frases típicas dos sujeitos pesquisados, na Classe 7, que os elementos autoestima, timidez, segurança, confiança e prazer estão relacionados ao desenvolvimento afetivo, contudo, eles não justificaram de forma consistente como esses elementos estão associados à prática pedagógica do professor de Educação Física.

As classes 6 e 7 apresentam um discurso genérico associando a dança ao desenvolvimento afetivo e, secundariamente, ao desenvolvimento social, o que aponta falta de ligação entre o que explicita as novas abordagens pedagógicas do campo da Educação Física, os documentos oficiais, e o que realmente os professores representam em sua prática. De acordo com Diniz e Darido (2012), as aulas de Educação Física ainda carregam fortes características esportivistas, deixando os outros elementos da cultura corporal como danças, capoeira, lutas, jogos, brincadeiras e ginásticas, que também deveriam ser tratados, excluídos ou minimamente abordados. Os autores também observam que, no geral, a dança se restringe às datas comemorativas, tornando-se desconexa de todo o projeto político pedagógico da escola e da própria Educação Física.

Analisando as Classes 1, 2, 6 e 7, observamos que os professores pesquisados possuem uma ideia genérica da prática do jogo de queimada, do jogo de futsal e da dança em relação ao desenvolvimento infantil. É possível perceber que quando se questiona o professor sobre a contribuição do jogo de futsal para o desenvolvimento do aluno, por exemplo, ele associa o futsal apenas à dimensão afetiva, sem uma explicação consistente.

\section{Bloco 2 - Estratégia, Raciocínio e Movimentos Corporais}

\section{Classe 4 - Título: Desenvolvimento cognitivo e habilidades cognitivas}

Esta classe apresenta um discurso típico do desenvolvimento cognitivo e parece organizado em torno do aprendizado de regras, da rapidez de raciocínio, da atenção e da capacidade de decisão (note-se que aqui as noções de grupo, coletividade ou cooperação estão ausentes, permitindo uma interpretação no sentido do desenvolvimento de habilidades centradas no indivíduo). Também se fazem presentes as noções de "tática" e "técnica". O desenvolvimento cognitivo aparece nessa situação dissociado de qualquer uma das atividades. Frases Típicas da Classe 4:

\footnotetext{
"Aprendizagem das regras, táticas, concentração, tomada de decisões rapidamente, criatividade."

"Facilidade de execução, através das estratégias dentro do jogo de como vencer o adversário, através do entendimento da formulação e aplicação de regras."

"Através do entendimento das regras e das funções exercidas durante o jogo."
}

Os discursos dos professores pesquisados, na Classe 4 apontam para um desenvolvimento cognitivo relacionado à aprendizagem e à aplicação das regras, táticas, concentração, tomada de 
decisões, ou seja, elementos isolados. Eles deveriam ser desenvolvidos dentro de uma base teórica, ligada a essas "habilidades cognitivas" com as outras dimensões do desenvolvimento.

Le Boulch (1983) e Fonseca (2012) explicam que o desenvolvimento cognitivo está entrelaçado com o desenvolvimento afetivo, motor e social dos alunos, pois é por meio do movimento que pode ser construído mais facilmente o esquema corporal, ou seja, a identificação das partes que compõem seu corpo, a diferenciação dos lados esquerdo e direito, o aprimoramento do equilíbrio, a melhora da coordenação motora ampla e fina, pois assim eles conseguem controlar melhor suas ações, suas atitudes e saber respeitar a opinião do outro.

\section{Classe 5 - Título: Desenvolvimento cognitivo e aptidões cognitivas}

Esta classe apresenta e reforça o discurso encontrado na Classe 4, centrado no desenvolvimento cognitivo, como que separado das atividades, destacando o planejamento, o controle, a organização temporal e a solução de problemas. Frases Típicas 5:

\footnotetext{
"Desenvolve a inteligência, o pensamento rápido, a da Classe capacidade de criar em pouco espaço de tempo, dentre outros."

"O aluno cria estratégias e planeja o jogo."

"Durante o jogo, o aluno desenvolve raciocínio para uma melhor execução da jogada, com o objetivo de vencer o jogo."

"Durante o jogo, o aluno desenvolve raciocínio para uma melhor execução da jogada, com o objetivo de vencer o jogo."
}

A partir das frases típicas dos sujeitos da pesquisa, na Classe 5, observamos uma desvinculação entre as contribuições do desenvolvimento cognitivo com relação ao desenvolvimento afetivo e social nas atividades jogo de queimada, jogo de futsal e dança. Identificamos que, quando os sujeitos pesquisados indicam o desenvolvimento da inteligência, do pensamento rápido, da capacidade de criatividade, na criação e planejamento de estratégias de jogo, eles desconsideram o fato de que essas aptidões cognitivas só acontecem se o professor de Educação Física tiver claro qual ou quais teorias estão embasando a sua aula.

Além disso, o desenvolvimento cognitivo está atrelado ao desenvolvimento social, por exemplo, à medida que o aluno joga ou dança, ele aprende a conviver com o outro, a se relacionar com o outro, respeitar o ponto de vista do próximo e, dessa forma, o professor de Educação Física pode estimular o aluno a ter atitudes de respeito mútuo e solidariedade para com o próximo e aprender a aceitar e conviver com diferentes grupos (BRASIL, 1998).

\section{Classe 3 - Título: Dança e desenvolvimento cognitivo}

Esta classe tem um peso secundário na constituição do bloco e apresenta um discurso que vincula dança e desenvolvimento cognitivo. Nesta classe, o discurso se organiza em torno da noção de "movimentos corporais", enfatizando o ritmo, o corpo, o movimento. Os indivíduos pesquisados afirmam que a dança é uma atividade que "explora o corpo", aponta a ideia de desenvolvimento do ritmo e da percepção corporal. Embora o desenvolvimento cognitivo apareça aqui como típico da classe, não é possível perceber, pelo conteúdo das palavras, uma associação direta entre este e os movimentos corporais. Supomos que ao serem demandados sobre o desenvolvimento cognitivo e a dança, os sujeitos se remetem ao movimento, ritmo e corpo, sem estabelecerem conexões consistentes. Frases Típicas da Classe 3:

"Improvisação, estratégias, tomada de decisão, ritmo, conhecimento dos diferentes tipos de dança e formas de movimentação do corpo." 
"Contribui para a memória, o raciocínio, a linguagem, a percepção, isso fazendo parte do desenvolvimento intelectual."

"Desenvolvimento de novas técnicas de dança e criatividade, conhecimento do corpo, aquisição de ritmo e coordenação, ritmo."

É importante frisar que a aula de Educação Física na escola deve assegurar aos alunos a (re)construção de um conjunto de conhecimentos que permitam ampliar sua consciência a respeito de seus movimentos e dos recursos para o cuidado de si e dos outros e desenvolver autonomia para a apropriação e a utilização da cultura corporal de movimento em diversas finalidades humanas, favorecendo sua participação de forma confiante e autoral na sociedade (BRASIL, 2017).

A dimensão cognitiva está identificada apenas nas atividades que envolvem grande atividade verbal/expositiva, vinculada aos jogos de regras ou a níveis mais elaborados dos jogos competitivos, que implicam no aprendizado de estratégias e regras. Neste caso, apontamos que o desenvolvimento cognitivo é percebido como dissociado das atividades pesquisadas (futsal, queimada e, em menor grau, a dança); como desvinculado das noções de grupo e coletividade.

Em relação à dimensão afetiva do desenvolvimento, a visão dos professores parece ser pouco clara, pois muitas vezes é associada à "cooperação" (como se o aprendizado da cooperação fosse produzido pelo "prazer de estar e jogar juntos"), sem especificar quais são os aspectos ou fatores afetivos na "coletividade"; a dimensão afetiva somente aparece como tal vinculada a uma noção genérica ou superficial de "atividade cultural" ou "diversidade cultural"; ou, ainda, muito frequentemente, ela é expressa na forma de lugares comuns da cultura: "aprender a vencer ou perder" ou "a dança trabalha a autoestima".

Desse modo, os Parâmetros Curriculares Nacionais de Educação Física (BRASIL, 1998) apontam que a prática da Educação Física deve contribuir para as transformações corporais, cognitivas, afetivas e sociais que ocorrem no aluno durante o Ensino Fundamental, proporcionando autonomia em relação ao próprio processo de aprendizagem que ele pode assumir em cada etapa da escolaridade, dando subsídios para que os processos de ensino e aprendizagem o incluam em relação interativa com os objetos de conhecimento da área. É fundamental que não se percam de vista a duração e a complexidade dessa interação, pois da mesma forma que os objetos de ensino transformam os sujeitos da aprendizagem, são, ao mesmo tempo, por eles transformados.

Com isso, podemos supor uma inconsistência entre as representações sociais do desenvolvimento e das atividades da aula de Educação Física, no sentido da pouca penetração das teorias do desenvolvimento ou da psicomotricidade nos discursos sobre as práticas. Outra hipótese seria conceber que a prática de Educação Física é enriquecida por diferentes visões ou abordagens.

Estudos afirmam (VASCONCELOS, CAMPOS, 2016; FORTES et al., 2012; MALDONADO et al., 2014) que os professores de EFe organizam e executam suas práticas em princípios metodológicos que não estão presentes em apenas uma das abordagens teóricas do campo da Educação Física, ou seja, há fortes indícios de um descompasso entre os discursos desses professores a respeito das intencionalidades e atividades educativas. Os limites conceituais referentes às abordagens, por exemplo, psicomotora, construtivista ou desenvolvimentista, não foram sequer mencionados nas representações sociais dos professores pesquisados. Neste caso, nos estudos de Vasconcelos e Campos (2016), Forte et al. (2012) e Maldonado et al. (2014) e no nosso estudo, o ensino das novas abordagens pedagógicas do campo da EFe parece não ter alcançado impacto suficiente na formação pedagógica dos professores pesquisados.

Identificou-se, portanto, uma lacuna relativa aos conhecimentos dos professores de Educação Física no que concerne às contribuições das atividades de jogo de futsal, jogo de queimada e dança para o desenvolvimento do aluno. Os resultados podem ser interpretados na 
direção de uma fragilidade na dimensão conceitual da prática pedagógica do professor de Educação Física.

\section{CONCLUSÃO}

Os dados do presente estudo apontam que as representações sociais das práticas pedagógicas estudadas estão dissociadas dos conhecimentos das novas abordagens pedagógicas do campo da EFe relacionadas ao desenvolvimento infantil, pois observarmos que os professores pesquisados possuem um conhecimento genérico acerca das contribuições do jogo de futsal, do jogo de queimada e da dança para o desenvolvimento integral do aluno; o genérico aqui é concebido não no sentido de amplo ou plural, mas difuso e superficial.

De modo geral, os discursos dos indivíduos pesquisados indicam uma prática pedagógica sem um embasamento teórico apropriado de como essas atividades contribuem para o desenvolvimento dos alunos, ficando relegados apenas à dimensão do "saber-fazer", repercutindo negativamente na legitimidade e na presença dessa disciplina na escola. Ainda podemos observar que não existe, nas falas dos professores, uma abordagem pedagógica apontando certa direção do objetivo a ser alcançado pelo ensino do jogo de futsal, do jogo de queimada e da dança. É possível levantar a hipótese de que sua visão do desenvolvimento se aproxima de uma visão "naturalista" da qual este seria o produto espontâneo, fruto automático ou mecânico das heranças genéticas ou determinado basicamente pela maturação orgânica. Tal hipótese aponta para a necessidade de mais pesquisas que aprofundem nosso conhecimento sobre a representação do desenvolvimento e da própria EFe.

É importante frisar que os sujeitos pesquisados associam, de maneira genérica, uma atividade a um aspecto do desenvolvimento psicomotor, como o desenvolvimento afetivo ao jogo de futsal, relatando que esse jogo trabalha o emocional da criança durante a partida, no intuito de saber lidar com a vitória ou a derrota, desenvolvendo ainda a cooperação, o respeito e a solidariedade. Também emergem dos discursos que, por se tratar de uma preferência dos alunos, este desenvolvimento naturalmente aparece na quadra. Esses relatos vão na contramão dos fundamentos que embasam a prática pedagógica do professor de Educação Física, pois ele deve intervir e oportunizar aos alunos a sistematização de objetivos, conteúdos, processos de ensino e aprendizagem e avaliação, tendo como meta a inclusão efetiva do aluno nas aulas de Educação Física, bem como estabelecer associações com os aspectos afetivo, cognitivo, motor e social dos alunos (BRASIL, 1998).

Um estudo que ajudaria a complementar a presente pesquisa seria o da representação social da formação pedagógica dos professores de Educação Física, pois reforçaria o que nós encontramos ou não. Portanto, uma questão importante a ser levantada é de que forma estão sendo apresentadas aos alunos de licenciatura em Educação Física as abordagens pedagógicas do campo da $\mathrm{EFe}$, que dão embasamento teórico para a prática pedagógica dos futuros professores e que contribuem para o desenvolvimento integral dos alunos. 


\section{REFERÊNCIAS}

ABRIC, Jean-Claude. Práticas sociales y representaciones. México: Presses Universitaires de France, 2001.

BARBOSA, Cláudio L. de Alvarenga. Educação Física escolar: as representações sociais. Rio de Janeiro: Shape, 2001.

BERTINI JUNIOR, Nestor; TASSONI, Elvira. A Educação Física, o docente e a escola: concepções e práticas pedagógicas. Rev. Bras. Educ. Fís. Esporte, (São Paulo) 2013, jul./set.; 27 (3): p. 467-83.

BETTI, Mauro. Educação física escolar: ensino e pesquisa-ação. 2. ed. Ijuí: Ed. Unijuí, 2013.

BETTI, Mauro; ZULIANI, Luiz Roberto. Educação Física escolar: uma proposta de diretrizes pedagógicas. Revista Mackenzie de Educaşão Física e Esporte - Ano 1, n. 1, 2002.

BRACHT, Valter. Educaşão física \& ciência: cenas de um casamento (in)feliz. 4. ed. Ijuí: Unijuí, 2014.

BRASIL. Ministério da Educação. Base Nacional Comum Curricular: Educação é a base. Brasília, 2017.

Disponível

em

http:/ portal.mec.gov.br/index.php?option $=$ com docman\&view $=$ download\&alias $=79601-$ anexo-texto-bncc-reexportado-pdf-2\&category slug=dezembro-2017-pdf\&Itemid=30192.

Acesso em 5 abr. 2020.

BRASIL. Lei n. 9.394, de 20 de dezembro de 1996. Estabelece as Diretrizes e Bases da Educação Nacional. Diário Oficial da União. Brasília, DF, v. 134, n. 248, p. 27833-841, 23 dez. 1996.

BRASIL. Secretaria de Educação Fundamental. Parâmetros curriculares nacionais: Educação Física. Secretaria de Educação Fundamental. Brasília: MEC/SEF, 1998.

COLL, Cesar et al. Desenvolvimento psicológico e educação. 2. ed. Porto Alegre: Artmed, 2004.

COTRIM, João Roberto et al. Desenvolvimento de habilidades motoras fundamentais em crianças com diferentes contextos escolares. Revista da Educação Física / UEM. Maringá, v. 22, n. 4, p. 523533, 4. trim. 2011.

CUNHA, Virgínia Maria. Repensando a avaliação: as representações sociais compartilhadas pelos professores de Educação Física. 2009. 168f. Tese (Doutorado em educação) - Pontifícia Universidade Católica, São Paulo.

DARIDO, Suraya Cristina; RANGEL, Irene Conceição. Educação Física na escola: implicações para a prática pedagógica. Rio de Janeiro: Guanabara Koogan, 2011.

DARIDO, Suraya Cristina; SOUZA JUNIOR, Osmar. Para ensinar Educação Física: possibilidades de intervenção na escola. Campinas, São Paulo: Papirus, 2011.

DINIZ, Irlla Karla; DARIDO, Suraya Cristina. Livro didático: uma ferramenta possível de trabalho com a dança na Educação Física escolar. Motriæ, Rio Claro, v. 18 n. 1, p. 176-185, jan./mar. 2012.

FONSECA, Vitor da. Manual de observação psicomotora: significação psiconeurológica dos fatores psicomotores. 2. ed. Rio de Janeiro: Wak Editora, 2012.

FORTES, Milena et al. A Educação Física escolar na cidade de Pelotas - RS: contexto das aulas e conteúdos. Rev. Educ. Fís / UEM, v. 23, n. 1, p. 69-78, 1. trim., jan./mar. 2012.

JESUINO, Jorge. Um conceito reencontrado. In: ALMEIDA, Angela Maria; SANTOS, Maria de Fátima; TRINDADE, Araujo (org.). Teoria das Representações Sociais: 50 anos. Brasília: Technopolitik, 2014. 
LAHLOU, Saadi. Difusão das representações e inteligência coletiva distribuída. In: ALMEIDA, Angela Maria; SANTOS, Maria de Fátima; TRINDADE, Araujo (org.). Teoria das Representações Sociais: 50 anos. Brasília: Technopolitik, 2014.

LE BOULCH, Jean. A educação pelo movimento: a psicocinética na idade escolar. Porto Alegre: Artes Médicas, 1983.

MALDONADO, Daniel Teixeira et al. As dimensões atitudinais e conceituais dos conteúdos na educação física escolar. Pensar a Prática, Goiânia, v. 17, n. 2, p. 546-559, jan./mar. 2014.

MOSCOVICI, Serge. A psicanálise, sua imagem e seu público. Petrópolis: Vozes, 2012.

PEREIRA, Giane Moreira. Representações sociais de Educação Física: o resgate e o remédio do corpo e da mente. Rio de Janeiro, Estácio de Sá (Mestrado em Educação), 2008.

PIAGET, Jean. A construção do real na criança. 3. ed. São Paulo, Ática, 2003.

PIAGET, Jean. Seis estudos de psicologia. 24. ed. Rio de Janeiro, Forense Universitária, 2007.

REINERT, Max. Un logiciel d'analyse lexicale. Les cabiers de l'analyse des données, tome 11, n. 4 (1986), p. $471-481$.

RETONDAR, Moebus José. As representações sociais do ato pedagógico dos professores de Educação Física que atuam no Ensino Fundamental no município do Rio de Janeiro. Motrivivência, ano XXI, n. 32-33, p. 211-229, jun./dez. 2009.

ROUQUETTE, Michel-Louis. Paradoxos da representação e da ação: conjunções sem coordenação. In: CAMPOS, Pedro Humberto; LOUREIRO, Marcos Corrêa (orgs.). Representações sociais e práticas educativas. Goiânia: Ed. da UCG, 2003.

SÁ, Ivo Ribeiro. Representações sociais: a Educação Física escolar em pauta. In: FONTOURA, P. (org.). Coleção Pesquisa em Educação Física. v. 4, p. 257-263, Jundiaí, São Paulo: Fontoura Ed., 2006.

TARDIF, Maurice. Saberes docentes e formação profissional. 17. ed. Petrópolis, Rio de Janeiro: Vozes, 2014.

TENÓRIO, Kadja Michele et al. Propostas curriculares para Educação Física em Pernambuco: entendimentos acerca do esporte. Rev. Bras. Ciênc. Esporte. 2015; 37 (3): p. 280-288.

VASCONCELOS, Maria; CAMPOS, Pedro Humberto. Educação Física escolar. seu campo e suas representações. Curitiba: Appris, 2016.

WATANABE, Márcia Massae; BIM, Ricardo Henrique. Propostas pedagógicas para o ensino da Educação Física na escola. Muita teoria e pouca prática (ainda)? Lecturas: Educación Física y Deportes. Buenos Aires, Año 16, n. 165, Febrero, 2012. Disponível em http://www.efdeportes.com/efd165/ensino-da-educacao-fisica-na-escola.htm. Acesso em 7 dez. 2018.

Submetido em outubro de 2019 Aprovado em maio de 2020 


\section{Informações dos autores}

Bruno Viviani dos Santos

Universidade Estácio de Sá (UNESA)

E-mail: brunoviviani prof@hotmail.com

ORCID: https://orcid.org/0000-0003-4982-1021

Link Lattes: http://lattes.cnpq.br/3199913272254818

Pedro Humberto Faria Campos

Universidade Estácio de Sá (UNESA)

E-mail: pedrohumbertosbp@terra.com.br

ORCID: https://orcid.org/0000-0002-0844-8358

Link Lattes: http://lattes.cnpq.br/4165413685802953 